\title{
Application of zeolite/kaolin combination for replacement of partial cement clinker to manufacture environmentally sustainable cement in Oman
}

\author{
Sabah A. Abdul-Wahab ${ }^{1^{\dagger}}$, Edris M. Hassan ${ }^{1}$, Khalifa S. Al-Jabri' ${ }^{2}$, Kaan Yetilmezsoy ${ }^{\dagger}$ \\ ${ }^{1}$ Department of Mechanical and Industrial Engineering, Sultan Qaboos University, P.O Box 33, PC 123, Muscat, Sultanate of Oman \\ ${ }^{2}$ Department of Civil and Architectural Engineering, P.O Box 33, PC 123, Muscat, Sultanate of Oman \\ ${ }^{3}$ Department of Environmental Engineering, Faculty of Civil Engineering, Yildiz Technical University, 34220, Davutpasa, Esenler, Istanbul, Turkey
}

\begin{abstract}
This study was conducted to explore the optimum proportion of zeolite and zeolite-kaolin as additives to cement clinker and gypsum samples, while maintaining the strength properties of produced environmentally sustainable cements. According to the British standard method, zeolite was added to cement clinker in proportions of $5-12 \%$ and $10-12 \%$ by weight, respectively, in the preparation of samples of zeolite-containing cement and zeolite-kaolin-based cement. Kaolin was used as a second additive as 10-20\% of the total weight. The compressive strength tests were performed on base cement samples according to a standard procedure given in ASTM C109 Compressive Strength of Hydraulic Cement. These values were compared with those of the reference sample and the Omani allowable limits. The results indicated that the best compressive strength values were obtained with $88 \%$ cement clinker, 5\% gypsum, and 7\% zeolite for the zeolite-containing cement. Quantities of 70\% cement clinker, $5 \%$ gypsum, $10 \%$ zeolite, and 15\% kaolin gave the best results for zeolite-kaolin-based cement, resulting in a substitution of than $25 \%$ cement clinker. The study concluded that the partial cement clinker replacement using zeolite/kaolin combination may have a great influence on the reduction of $\mathrm{CO}_{2}$ emission and energy saving in cement manufacturing.
\end{abstract}

Keywords: Compressive strength, Kaolin, Low cement clinker content, Low $\mathrm{CO}_{2}$ emissions, Synthetic zeolite

\section{Introduction}

Cement plants have considerable environmental impacts as they produce large quantities of $\mathrm{CO}_{2}$, which is responsible for the greenhouse effect. It is thought that the cement industry sector represents $5-7 \%$ of overall anthropogenic $\mathrm{CO}_{2}$ releases [1]. Many studies have been done to evaluate $\mathrm{CO}_{2}$ emissions and the consumption of energy [1-3]. In particular, during the cement manufacturing process, $\mathrm{CO}_{2}$ is emitted by different sources $[4,5]$, and it has been estimated that around $850 \mathrm{~kg}$ of $\mathrm{CO}_{2}$ are emitted per ton of cement clinker produced in the manufacture of Portland cement.

The raw materials employed for cement production consist of 80\% limestone $\left(\mathrm{CaCO}_{3}\right)$ and $20 \%$ clay [2]. Clay contains mainly three oxides: silica $\left(\mathrm{SiO}_{2}\right)$, alumina $\left(\mathrm{Al}_{2} \mathrm{O}_{3}\right)$ and iron $\left(\mathrm{Fe}_{2} \mathrm{O}_{3}\right)$ [1, 2]. The cement manufacturing process consists of three main stages: preparation and milling of raw materials, production of the cement clinker (pyro-processing or clinkerization) and grinding and blending of the cement clinker [4]. In the third stage, Portland cement is produced by inter-grinding $95 \%$ of the cement clinker and 5\% gypsum [2, 3]. At this final stage, different additives can be used as partial replacement of cement clinker to produce environmentally friendly cements with low cement clinker content that will lead in turn to the reduction of $\mathrm{CO}_{2}$ released into the atmosphere [5, 6]. This partial substitution of one or more additives for cement clinker results in a reduction in $\mathrm{CO}_{2}$ emission and energy saving in cement manufacture and provides heavier-duty cements that can be used in the construction industry.

Previous research has shown that the cement industry plays a leading role in waste utilization [7]. This is because of the abnormal types of the processes that are involved in its rotary kiln unit
This is an Open Access article distributed under the terms of the Creative Commons Attribution Non-Commercial License (http://creativecommons.org/licenses/by-nc/3.0/) which permits unrestricted non-commercial use, distribution, and reproduction in any medium, provided the original work is properly cited.

Copyright (C) 2019 Korean Society of Environmental Engineers
Received January 24, 2018 Accepted July 26, 2018

${ }^{\dagger}$ Corresponding author

Email: sabah1@squ.edu.om, yetilmez@yildiz.edu.tr ; kyetilmezsoy@gmail.com Tel: +90-212-383-5376 Fax: +90-212-383-5358

ORCID: 0000-0003-1478-9957 (K. Yetilmezsoy) 
which allow incorporation of different waste materials. In addition, the cement clinker has the capability to absorb other materials. This is mainly due to a high kiln temperature $\left(1,450-1,500^{\circ} \mathrm{C}\right)$ and the chemical properties of the cement clinker [6, 8]. In general, industrial waste can be utilized in a cement plant for three different applications: as partial substitution for raw materials in the kiln feed to produce cement clinker; as partial substitution for cement clinker to compose a portion of final cement product; and as an alternative fuel source.

The main two ingredients of cement are clinker (95\%) and gypsum (5\%). Each must have a specific proportion to produce an acceptable quality of cement according to recognized international standards. As mentioned earlier, however, the cement clinker production process generates large quantities of $\mathrm{CO}_{2}$. Therefore, since cement clinker is the key source of $\mathrm{CO}_{2}$, a good approach to reducing $\mathrm{CO}_{2}$ emissions during cement manufacturing may be to use less cement clinker. According to the findings of an industrial trial which aimed to produce a low-clinker, low-carbon cement, $\mathrm{CO}_{2}$ reduction can be reached with the use of cement clinker substitutes [9]. This partial cement clinker replacement will not only help decrease $\mathrm{CO}_{2}$ emissions but also reduce costs due to the lower energy consumption during calcining and grinding [10]. Using industrial waste in cement manufacturing could reduce the environmental impact and cement production costs and make the cement more durable and efficient [11].

The use of different industrial waste products as additives in the manufacture of cement has garnered significant consideration throughout recent years [12]. Fly ash and blast furnace slag [3], natural perlite [10], limestone [13], volcanic scoria [14, 15], ternary binders such as cement/blast furnace slag/flash metakaolin [16], spent alumina catalyst and fluidized cracking catalyst [17], natural zeolite, coal bottom ash and fly ash materials [18], blast furnace slag, raw zeolite and municipal solid waste incineration fly ash [19], waste glass [20], coal combustion ash [7], and red mud [21] constitute the industrial waste products used. These waste materials are extremely attractive for their hydraulic and/or pozzolanic activities [22]. Evidently, different replacement additives have dissimilar impacts on cement's properties owing to their different physical, chemical, and mineralogical characteristics [19, 23-25]. This fact has directed many researchers towards searching for new waste materials that would be suitable for sustainable cement production. In pursuit of this end, experimental studies must be conducted to find suitable partial substitutes among these industrial waste products to ensure that their utilization would be valid and appropriate for sustainable cement manufacturing [4]. Such products could be used to partially replace cement clinker without affecting the quality and price of cement.

There are many reasons behind selecting zeolite catalysts as additives in this work. Large quantities of zeolite catalysts are generated as industrial by-products in Oman. They are by-products of the residue fluidized catalytic cracking process carried out in Oman's refineries and petroleum industries. Generally, disposal sites are needed for the final disposal of this waste. According to Sohar Refinery, it generates 18-20 tons of zeolite catalyst per day. Therefore, Sohar Refinery is looking for solutions to recycle the catalyst and diminish its accumulation in disposal sites. Consequently, the utilization of zeolite in the cement industry makes good economic sense in managing waste and reducing the cement industry's demand for raw materials. From the viewpoint of recycling, this can be considered a sustainable approach to manage waste and reduce the amount sent for final disposal to a minimum. It would also aid in the development of cement whose manufacture is more sustainable and less damaging to the environment with lower emissions of $\mathrm{CO}_{2}$. Moreover, zeolite catalysts are materials used in oil refineries for catalytic reactions. They are suitable materials that can partially replace the clinker in the cement production because they have some similar physical and chemical characteristics to that of cement. More than $80 \%$ of zeolite catalysts' contents are silicate and aluminate, which are basic constituents that are required in the cement industry. However, zeolite can substitute for only a limited percentage of cement clinker $(\leq 7 \%)$ since the extra addition of zeolite to the cement clinker will have an undesirable effect on the compressive strength of produced cement. This is mainly because zeolite does not contribute to the strength of the cement. Adding more zeolite on the expense of the cement clinker will lead to less hydration reaction, causing lower compressive strength values of the produced cement.

As a result, in the present work, kaolin in combination with zeolite catalyst was added to the cement clinker to be mixed in different proportions to enhance the cement's compressive strength. The partial substitution of kaolin and zeolite for cement clinker will retain the strength of the zeolite-containing cement. The reason for selecting kaolin as a second additive is that it is a good source of alumina and silica. Kaolin is thermally activated when heated to $650-850^{\circ} \mathrm{C}$ for 1-2 h. In addition, the composition of kaolin is similar to that of cement, which finesses it and makes it consistent with cement.

To reduce $\mathrm{CO}_{2}$ emissions, some additives can be used in the last stage of cement manufacturing after cement clinker production. These additives must replace a certain percentage of cement clinker to reduce $\mathrm{CO}_{2}$ emission. Additives should be mixed with cement clinker and gypsum in proper proportions to get cement with good properties. This paper focuses on a specific application (partial cement clinker replacement), where the industrial waste will be mixed in a suitable proportion with the cement clinker, thus composing a portion of the Portland cement product [4]. Therefore, partial replacement of cement clinker with industrial waste products in Portland cement has been a topic ripe for exploration due to both environmental causes and practicality. This approach would result in producing cement with a low clinker content, also allowing an associated reduction in energy requirements and a subsequent decrease in $\mathrm{CO}_{2}$ kiln emissions released to the atmosphere.

In this study, both a zeolite catalyst and kaolin were selected as additives to substitute partially for cement clinker. The additives were added when the cement clinker was mixed with gypsum. The objective of the current study was to indicate the optimum proportion of zeolite and zeolite-kaolin needed to produce environmentally friendly cements, while maintaining the strength properties of produced cements. The study was basically carried out to fulfill a research gap in this field by focusing upon the possibility of using zeolite and kaolin as partial replacement of cement clinker and studying the effect of this addition on the compressive strengths of the produced cements. The results of the study will help in determining the effect of adding such additives to cement manufacturing to produce a sustainable cement with a low clinker content that will result in reducing the $\mathrm{CO}_{2}$ released into the atmosphere. 


\section{Materials and Methods}

Cement clinker produced by the Oman Cement Company (OCC) was used in this study for the preparation of mixture samples. Kaolin was also collected from the OCC as the company obtains it in its raw form from mountains in Oman. The used zeolite was the spent hydro-processing catalyst generated in Oman by the petroleum refining industry. In Oman, there are two oil refineries. The first refinery is located in Mina Al-Fahal whereas the second one is located in Sohar. Currently, these two refineries both belong to the Oil Refineries and Petroleum Industries Company (ORPIC). A large amount of zeolite catalyst is generated from those refineries, but the majority of zeolite catalysts are generated in Sohar. The type of synthetic zeolite additive used in this study, called synthetic zeolite, is a by-product of residue fluidized catalytic cracking (RFCC), which was obtained from ORPIC. It is mainly made up of $\mathrm{SiO}_{2}$ and $\mathrm{Al}_{2} \mathrm{O}_{3}$, which are basic constituents that are necessary in the cement manufacturing. The structural feature of the synthetic zeolite used in this study was reported by McCusker et al. [26]. Details about its chemical composition can be found in Zhdanov et al. [27].

It should be noted that in this study, a combination of zeolite and kaolin was added to this clinker produced by OCC to study the effect of this addition on the strength and durability of produced Portland cement. The procedure for cement preparation used in this study is shown in Fig. 1. Cement clinker, gypsum, and additives (zeolite and kaolin) are mixed together in the required proportions to produce the final cement product.

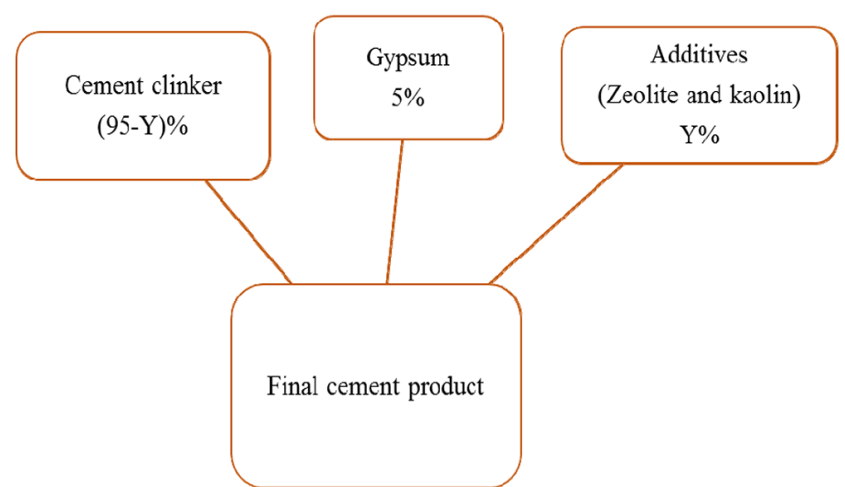

Fig. 1. The procedure for cement preparation used in this study $(Y$ denotes the varying percentage of zeolite or zeolite-kaolin additives to cement clinker and gypsum samples).

\subsection{Zeolite Sample Preparation}

Four samples of zeolite-containing cement were prepared to conduct compressive strength tests. For each of these samples, zeolite catalyst was added to cement clinker in different proportions of $5 \%, 7 \%$, $10 \%$, and $12 \%$ by weight. In addition, one sample was prepared as a reference sample containing $0 \%$ zeolite catalyst (Sample 1: C95G5Z0K0). In this experimental work, the British standard method was followed. Details of the zeolite-added mixes (Samples 2-5) are given in Table 1 for cement clinker (C), gypsum (G), and zeolite (Z), respectively.
Table 1. Main Variations (given as notations) of Each Component of Cement for Each Sample

\begin{tabular}{lc}
\hline Sample number & $\begin{array}{c}\text { Cement content (\%) } \\
\text { (cement clinker, gypsum, zeolite, kaolin) }\end{array}$ \\
\hline 1 (Reference) & C95G5Z0K0 \\
2 & C90G5Z5K0 \\
3 & C88G5Z7K0 \\
4 & C85G5Z10K0 \\
5 & C83G5Z12K0 \\
6 & C75G5Z10K10 \\
7 & C70G5Z10K15 \\
8 & C65G5Z10K20 \\
9 & C73G5Z12K10 \\
10 & C68G5Z12K15 \\
11 & C63G5Z12K20 \\
\hline
\end{tabular}

\subsection{Zeolite-Kaolin Sample Preparation}

To enhance the compressive strength of the produced cement, kaolin was heated to $650^{\circ} \mathrm{C}$ for $2 \mathrm{~h}$ and then used to prepare samples 6-11 (Fig. 2(a) and 2(b)). Zeolite was added to cement clinker in proportions of $10 \%$ and $12 \%$ by weight. In these experiments, the kaolin was used as a second additive as $10 \%, 15 \%$, and $20 \%$
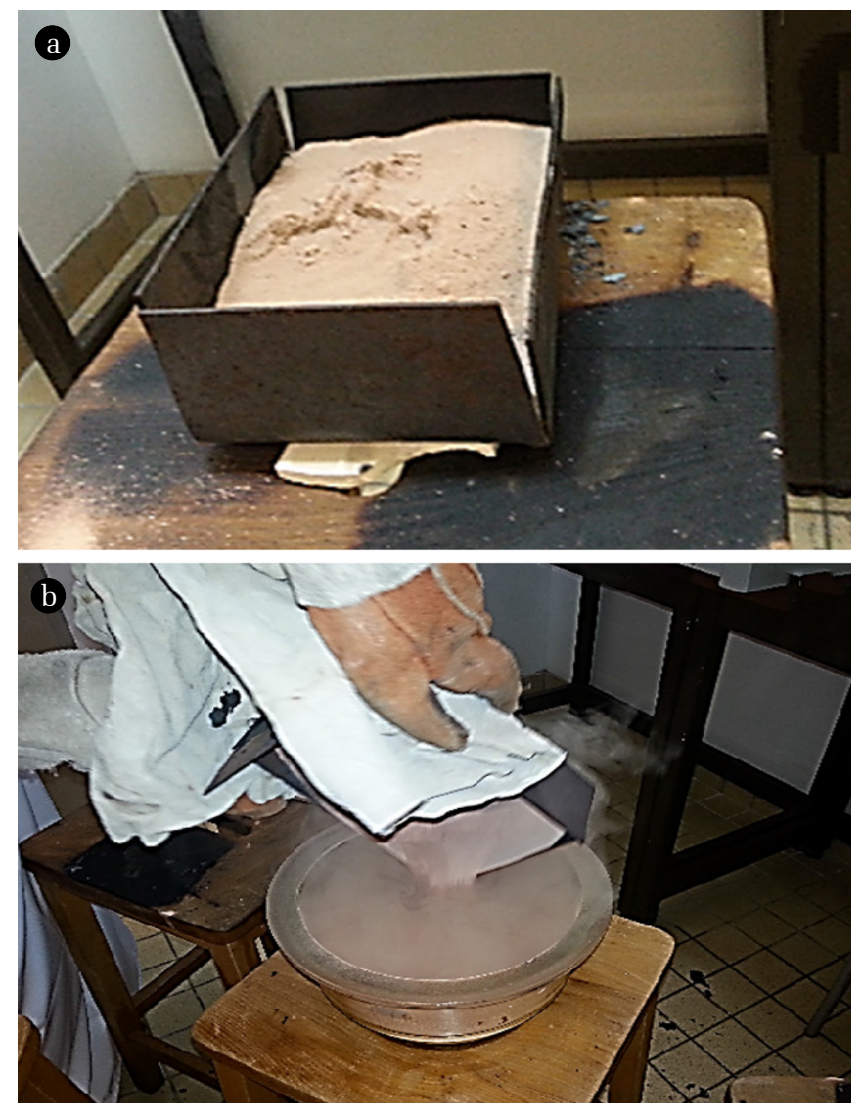

Fig. 2. (a) Kaolin before heating, (b) kaolin after heating. 
of the total weight. Details of the zeolite/kaolin-added mixes (Samples 6-11) are presented in Table 1 for cement clinker (C), gypsum $(\mathrm{G})$, zeolite $(\mathrm{Z})$, and kaolin $(\mathrm{K})$, respectively.

\subsection{Compressive Strength Test}

Compressive strength is the ability of materials or structures to support loads that have a tendency to reduce in size. The compressive strength tests were conducted on base cement samples according to a standard procedure described in ASTM C109 Compressive Strength of Hydraulic Cement [28]. First, $450 \mathrm{~g}$ of cement, 1,350 g of standard sand, and $225 \mathrm{~g}$ of water were combined in a mixer. It should be noted that the standard sand used as recommended by ASTM/API. The mortar was then placed on a mould with dimensions of $40 \times 40 \times 160 \mathrm{~mm}$ (Fig. 3(a)). The bubbles and gases were removed by vibration using a jolting machine (Fig. 3(b)). After finishing the jolting process, the extra material on top of the mould was removed by drawing a straight edge with a sawing motion. After that, the mould was placed in a moist curing chamber for $24 \mathrm{~h}$ with a temperature of $20^{\circ} \mathrm{C}$ and a humidity level of more than 95\% to avoid any evaporation of water (Fig. 3(c)). After $24 \mathrm{~h}$, the cubes were hardened. They were then removed from moulds and placed in an accelerated water curing tank for 2, 7, and $28 \mathrm{~d}$ of curing. The compressive strength test was conducted with a compressive test machine by applying a relative load rate of $2 \mathrm{kN} / \mathrm{s}$ until the cube started to fracture (Fig. 3(d)). The compressive strength was calculated by dividing the load by the cross-section area $(40 \times 40 \mathrm{~mm})$. Results presented in this study were confirmed throughout repetitive experimental work.

\section{Results and Discussion}

\subsection{Compressive Strength of Different Cement Samples}

The compressive test results of experimental cement samples measured at curing ages of 2, 7, and $28 \mathrm{~d}$ of curing are given in Table 2 and Fig. 4. Reference mixture samples without any added zeolite or kaolin were used as benchmark samples. It should be noted that the compressive strength in these reference mixture samples
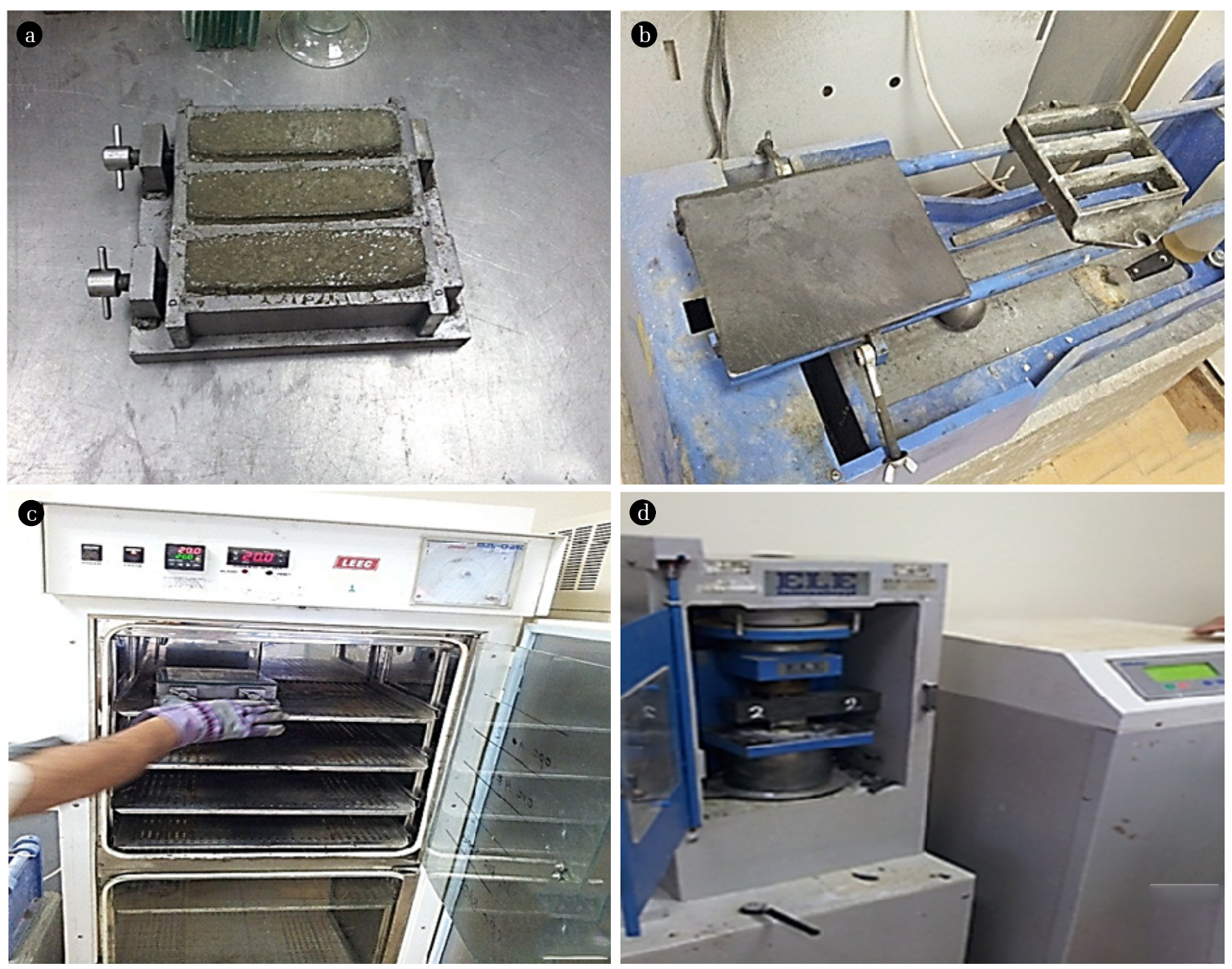

Fig. 3. (a) Samples placed in mould, (b) jolting machine, (c) samples stored in moist curing chamber, and (d) compressive testing machine and digital load recorder. 
Table 2. Compressive Strength $\left(\mathrm{N} / \mathrm{mm}^{2}\right)$ after 2, 7, and 28 Days

\begin{tabular}{|c|c|c|c|c|}
\hline \multirow{2}{*}{ Sample number } & \multirow{2}{*}{$\begin{array}{c}\text { Cement content (\%) } \\
\text { (cement clinker, gypsum, zeolite, kaolin) }\end{array}$} & \multicolumn{3}{|c|}{ Compressive strength $\left(\mathrm{N} / \mathrm{mm}^{2}\right)$} \\
\hline & & $2 \mathrm{~d}$ & $7 \mathrm{~d}$ & $28 \mathrm{~d}$ \\
\hline 1 (Reference) & C95G5Z0K0 & 17.1 & 32.8 & 42.8 \\
\hline 2 & C90G5Z5K0 & 17.1 & 32.5 & 41.8 \\
\hline 3 & C88G5Z7K0 & 15.3 & 29.0 & 41.9 \\
\hline 4 & C85G5Z10K0 & 11.2 & 23.4 & 35.0 \\
\hline 5 & C83G5Z12K0 & 10.6 & 22.5 & 35.9 \\
\hline 6 & C75G5Z10K10 & 18.8 & 34.4 & 48.4 \\
\hline 7 & C70G5Z10K15 & 16.3 & 29.7 & 49.3 \\
\hline 8 & C65G5Z10K20 & 10.9 & 21.3 & 37.8 \\
\hline 9 & C73G5Z12K10 & 12.5 & 23.4 & 39.7 \\
\hline 10 & C68G5Z12K15 & 9.4 & 18.4 & 32.8 \\
\hline 11 & C63G5Z12K20 & 11.6 & 22.1 & 37.8 \\
\hline \multicolumn{2}{|r|}{ Omani allowable limits } & $>10 \mathrm{MPa}$ & $>25 \mathrm{MPa}$ & $>42.5 \mathrm{MPa}$ \\
\hline
\end{tabular}

depends primarily on the hydration rate of cement clinker only. According to the test results, the addition of only zeolite (Samples 2-5) led to a noticeable fall in the compressive strength values of produced cement with regard to the reference mixture samples. At all testing ages, the reference samples (95\% cement clinker and 5\% gypsum) showed higher values of compressive strength than those of zeolite-containing cement sample mixtures. A reduction of compressive strength was observed at all testing ages and was more noticeable when a higher percentage of zeolite was used. At all testing ages, the compressive strength of the zeolite-containing cement reduced with regard to the reference mixture when the ratio of zeolite increased.

Although the mixture with 5\% zeolite (Sample 2: C90G5Z5K0) revealed nearly identical consequences to the reference samples, the results indicated that the addition of zeolite, especially in the larger amount of $12 \%$, led to pronounced negative effects on the compressive strength of the produced cement (Sample 5: C83G5Z12K0) at all testing ages. Therefore, the lowest value of

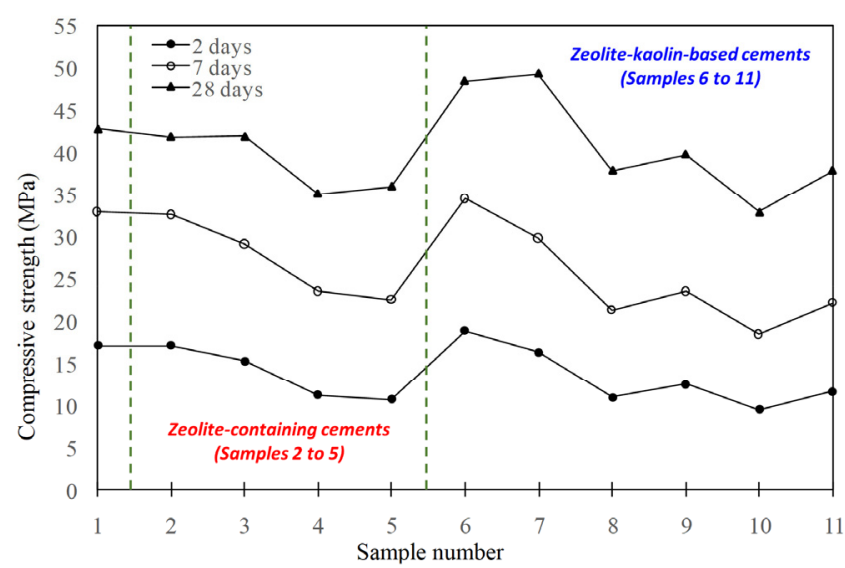

Fig. 4. Compressive strength (MPa) of different cement samples at curing ages of 2,7 , and $28 \mathrm{~d}$. compressive strength at all testing ages was for Sample 5. The poor performance of Sample 5 was due to its high zeolite content, which contributed negatively to strength at all ages. It seems that the level of zeolite in the sample tended to delay compressive strength development.

For all percentages of zeolite ( $5 \%, 7 \%, 10 \%$, and $12 \%$ ), although a reduction in compressive strength value was observed, the resulted cement satisfied the Omani allowable limits of the compressive strength for testing a 2-day curing age ( $>10 \mathrm{MPa}$ ). On the other hand, when curing ages reached 7 and $28 \mathrm{~d}$, a clear decrease in the usefulness of the zeolite-containing cement was seen, and the observed values were less than the Omani allowable limits (> $25 \mathrm{MPa}$ and $>42.5 \mathrm{MPa}$, respectively) upon adding $10 \%$ or more zeolite. This observation indicated that up to $7 \%$ zeolite can be introduced without disturbing the compressive strength values of the produced cement. In a previous study, Ozvan et al. [29] investigated the potential effects of using scoria (a natural material of volcanic origin used in cement industry as natural pozzolan) as supplementing cementitious material and its amount on the compressive strength of concrete. The authors observed a similar decrease in the compressive strength of 40 and 50\% scoria-added concrete mixtures and concluded that more than a certain amount (up to $30 \%$ ) of additive replacement was not suitable for structural concrete. In another study, Zaharaki and Komnitsas [30] aimed to evaluate the effect of various additives (e.g., kaolinite, pozzolan, fly ash, red mud, $\mathrm{CaO}$, pulverized silica sand or commercial glass) on the compressive strength of inorganic polymers synthesized using low Ca electric arc ferronickel slag and alkali activating solutions. Likewise, they emphasized that the compressive strength dropped slightly when the quantity of the additive was increased to a certain percentage (up to $20 \%$ ) by weight. Similar results, which are in line with the findings obtained in the present study, were also reported in other studies [31, 32].

For all testing ages, the best compressive strength values were obtained from cement produced with $88 \%$ cement clinker, 5\% gypsum, and 7\% zeolite (Sample 3: C88G5Z7K0). The cement clinker 
percentage, therefore, was reduced from $95 \%$ to $88 \%$, which means an equivalent reduction in $\mathrm{CO}_{2}$ emissions will be achieved. It is worth mentioning here that the compressive strength of the zeolite-containing cement depends mainly on the combination of cement hydration and the pozzolanic activity of zeolite. On the other hand, pronounced positive effects on compressive strength values were obtained when adding zeolite and kaolin together to the cement clinker samples. In a previous study regarding the simultaneous effect of silica fume and limestone on compressive strength and sulfate resistance of mortars, a similar phenomenon was observed by İnan Sezer [33]. With the addition of kaolin, there was a persistent enhancement of the performance of the mixtures, and the observed values of Samples 6 and 7 (C75G5Z10K10 and C70G5Z10K15) complied well with the Omani allowable limits at all testing ages. This finding is consistent with the results by Kamarudin et al. [34], who asserted that the kaolin binder showed an adequate compressive strength and could be utilized for non-loading environmentally friendly construction materials.

For Samples 6 and 7, the compressive strength values of all the cement mixtures were better than the values found in the reference samples. This spectacular increase in the performance of the mixtures of Samples 6 and 7 was noticed at the age of $7 \mathrm{~d}$. When curing ages were extended to 7 and $28 \mathrm{~d}$, comparable common attitudes as in the 2-day strength data was also spotted. This was possibly attributable to the large pozzolanic reactivity of zeolite and kaolin in combination. Together, they possessed sufficient pozzolanic characteristics to be used in the production of cement. For all testing ages, the best compressive strength values were obtained from cement produced with 70\% cement clinker, 5\% gypsum, 10\% zeolite, and 15\% kaolin (Sample 7: C70G5Z10K15). The cement clinker percentage, therefore, was reduced from $95 \%$ to $70 \%$, resulting in a $25 \%$ reduction in $\mathrm{CO}_{2}$ emissions.

\subsection{Zeolite-containing Cements}

In the first set of experiments, only zeolite was used to replace cement clinker at $5 \%, 7 \%, 10 \%$, and $12 \%$, and the properties of the produced zeolite-containing cements were examined at 2, 7 and $28 \mathrm{~d}$ for compression. When the zeolite was present at $5 \%$ of the total mixture, the compressive strength of the mixtures got closer to that of the reference samples. Generally, it was found at all curing ages that the compressive strength values decreased with respect to the reference mixtures upon incorporation of zeolite at $7 \%$ or above. Lower compressive strength was observed with respect to the corresponding reference samples for higher additions of zeolite. For the age of $2 \mathrm{~d}$, the inclusion of zeolite at $7 \%$ or above resulted in a reduction in compression. However, the values were still acceptable as they were above the Omani allowable limit of $>10 \mathrm{MPa}$. On the other hand, when curing was extended to 7 and $28 \mathrm{~d}$, the addition of zeolite at $10 \%$ or above showed poor performance and was found to have a disadvantageous influence on the strength of the sample mixtures. The values did not satisfy the Omani allowable limits (i.e., $25 \mathrm{MPa}$ at $7 \mathrm{~d}$ of age, and 42.5 $\mathrm{MPa}$ at $28 \mathrm{~d}$ of age). The optimum substitution of zeolite was determined to be $7 \%$ for all ages and required cement to contain at least $88 \%$ cement clinker. In this category, the cement clinker percentage was reduced from $95 \%$ to $88 \%$, meaning the attainment of a $7 \%$ reduction in $\mathrm{CO}_{2}$ emissions.

\subsection{Zeolite-Kaolin-based Cements}

In the second set of experiments, to overcome the disadvantages of the low compressive strength values of cement containing zeolite, kaolin was added as a second additive to the binder sample mixtures. The properties of the zeolite-kaolin-based cements were then investigated and reported through compression. Kaolin's effect on compression was investigated with its addition constituting 10\%, 15\%, and $20 \%$ of the total weight in combinations of $10 \%$ and $12 \%$ zeolite. The addition of kaolin in the appropriate proportions with zeolite to the cement clinker was found to be effective on compression as it provided a significant improvement of the strength of the cement. Quantities of 10\% zeolite and 10-15\% kaolin gave the best results. In a similar study, Ilić et al. [35] explored the effect of metakaolin and mechanically activated kaolin as cement replacement materials on cement strength and microstructure under different curing conditions. The authors obtained the highest compressive strength for mortar with $10 \%$ of mechanically activated kaolin, which is compatible with the quantity of kaolin determined in the present study. It is noted that the zeolite-kaolin-based cement enabled the substitution of more than $25 \%$ cement clinker (i.e., from $95 \%$ to $70 \%$ ) without compromising performance. This improvement in cement manufacturing with a low cement clinker content may have a great influence on the reduction of $\mathrm{CO}_{2}$ emissions.

\section{Conclusions}

This study was undertaken to determine the compressive strength values of different cement samples prepared with different percentages of zeolite and kaolin which were added to different cement clinker samples in varying proportions. The compressive strength values of these samples were then compared with those of the corresponding properties of the reference samples and with the Omani allowable limits. The study was aimed to find the best acceptable zeolite and zeolite/kaolin combination that can be added as a partial replacement for cement clinker in cement production for improving the sustainability of cement manufacturing in Oman and the world. Based on the experimental findings, the main conclusions obtained within the framework of this study were drawn as follows:

i) For all testing ages of zeolite-containing cement mixture, the best compressive strength values were obtained with cement mixture quantities of $88 \%$ cement clinker, $5 \%$ gypsum, and $7 \%$ zeolite. The cement clinker percentage, therefore, was reduced from $95 \%$ to $88 \%$, which means an equivalent reduction in $\mathrm{CO}_{2}$ emissions will be achieved.

ii) The cement mixture of $70 \%$ cement clinker, $5 \%$ gypsum, $10 \%$ zeolite, and $15 \%$ kaolin gave the best results for zeolite-kaolin-based cement mixture. This zeolite-kaolin-based cement enabled the substitution of more than $25 \%$ cement clinker without disturbing the compressive strength values of the produced cement.

iii) Cement mixtures obtained with partial replacement of cement clinker with up to $7 \%$ zeolite, or $10 \%$ zeolite $+10 \%$ kaolin, or 
$10 \%$ zeolite $+15 \%$ kaolin provided adequate compressive strength and required less cement clinker.

iv) Use of locally available materials, such as zeolite and kaolin, was found to be a suitable option to produce cement with a low cement clinker content. Partial cement clinker replacement using these additives may have a great influence on energy saving and the reduction of $\mathrm{CO}_{2}$ emission in cement manufacturing.

v) It is believed that the experimental findings obtained within the scope of this study will play a leading role in encouraging the use of zeolite and kaolin to manufacture environmentally sustainable cement in Oman and the world. This will result in reducing the amount of cement clinker needed as well as saving in significant amounts of natural resources used currently in cement manufacturing.

\section{Acknowledgments}

The authors would like to thank the anonymous reviewers for their valuable comments and suggestions to improve the quality of the manuscript.

\section{References}

1. Chen C, Habert G, Bouzidi Y, Jullien A. Environmental impact of cement production: Detail of the different processes and cement plant variability evaluation. J. Clean. Prod. 2010;18:478-485.

2. Abdul-Wahab SA, Al-Rawas GA, Ali S, Al-Dhamri H. Impact of the addition of oil-based mud on carbon dioxide emissions in a cement plant. J. Clean. Prod. 2016;112:4214-4225.

3. Chen IA, Juenger MCG. Incorporation of waste materials into portland cement clinker synthesized from natural raw materials. J. Mater. Sci. 2009;44:2617-2627.

4. Benhelal E, Zahedi G, Shamsaei E, Bahadori A. Global strategies and potentials to curb $\mathrm{CO}_{2}$ emissions in cement industry. J. Clean. Prod. 2013;51:142-161.

5. Kaddatz KT, Rasul MG, Rahman A. Alternative fuels for use in cement kilns: Process impact modelling. Procedia Eng. 2013;56:413-420.

6. Mokrzycki E, Uliasz-Bocheńczyk A. Alternative fuels for the cement industry. Appl. Energ. 2003;74:95-100.

7. Marroccoli M, Pace ML, Telesca A, Valenti GL, Montagnaro F. Utilization of coal combustion ashes for the synthesis of ordinary and special cements. Combust. Sci. Technol. 2010;182:588-599.

8. Bernardo G, Marroccoli M, Nobili M, Telesca A, Valenti GL. The use of oil well-derived drilling waste and electric arc furnace slag as alternative raw materials in clinker production. Resour. Conserv. Recycl. 2007;52:95-102.

9. Vizcaíno-Andrés LM, Sánchez-Berriel S, Damas-Carrera S, Pérez-Hernández A, Scrivener KL, Martirena-Hernández JF. Industrial trial to produce a low clinker, low carbon cement. Mater. De Constr. 2015;65:1-11.

10. Erdem TK, Meral C, Tokyay M, Erdogan TY. Use of perlite as a pozzolanic addition in producing blended cements. Cement Concrete Compos. 2007;29:13-21.
11. Dong-xu L, Lin C, Zhong-zi X, Zhi-min L. A blended cement containing blast furnace slag and phosphorous slag. J. Wuhan Univ. Technol.-Mater. Sci. Ed. 2002;17:62-65.

12. Kula I, Olgun A, Erdogan Y, Sevinc V. Effects of colemanite waste, cool bottom ash, and fly ash on the properties of cement Cement Concrete Res. 2001;31:491-494.

13. Beddar M, Meddah A, Boubakria M, Haddad N. A study of the effects of partial replacement of clinker by limestone in the cement manufacture. Cement Wapno Beton 2014;81: 185-193.

14. Al-Swaidani AM, Aliyan SD. Effect of adding scoria as cement replacement on durability-related properties. Int. J. Concr. Struct. Mater. 2015;9:241-254.

15. Al-Swaidani AM, Aliyan SD, Adarnaly N. Production of more sustainable mortar using finer volcanic scoria-based blended cements. J. Sust. Archit. Civil Eng. 2015;4:49-61.

16. Cassagnabère F, Mouret M, Escadeillas G, Broilliard P, Bertrand A. Metakaolin, a solution for the precast industry to limit the clinker content in concrete: Mechanical aspects. Constr. Build. Mater. 2010;24:1109-1118.

17. Al-Dhamri H, Melghit K. Use of alumina spent catalyst and RFCC wastes from petroleum refinery to substitute bauxite in the preparation of Portland clinker. J. Hazard. Mater. 2010;179: 852-859.

18. Canpolat F, Yilmaz K, Köse MM, Sümer M, Yurdusev MA. Use of zeolite, coal bottom ash and fly ash as replacement materials in cement production. Cement Concrete Res. 2004;34:731-735.

19. Luhowiak W, Kadri EH, Lefevre A, Petruk MP, Sobol K. Use of municipal solid waste incineration (MSWI) fly ash for manufacturing ecological and energy saving cements. International Concrete Abstracts Portal: American Concrete Institute (ACI). Special Publication 2004;221:443-456.

20. Sobolev K, Türker P, Soboleva S, Iscioglu G. Utilization of waste glass in ECO-cement: Strength properties and microstructural observations. Waste Manage. 2007;27:971-976.

21. Liu X, Zhang N. Utilization of red mud in cement production: A review. Waste Manage. Res. 2011;29:1053-1063.

22. Bilodeau A, Mohan Malhotra V. High-volume fly ash system: Concrete solution for sustainable development. ACI Struct. J. 2000;97:41-48.

23. Berra M, Mangialardi T, Paolini AE. Reuse of woody biomass fly ash in cement-based materials. Constr. Build. Mater. 2015;76:286-296.

24. Demirbaş A. Optimizing the physical and technological properties of cement additives in concrete mixtures. Cement Concrete Res. 1996;26:1737-1744

25. Stoitchkov V, Abadjiev P, Lilkov V, Vasileva V. Effect of the "pozzolit" active mineral admixture on the properties of cement mortars and concretes part 1: Physical and mechanical properties. Cement Concrete Res. 1996;26:1065-1071.

26. McCusker LB, Olson DH, Baerlocher C. Atlas of zeolite framework types (book). 2007.

27. Zhdanov SP, Khvoshchev SS, Feoktistova NN. Synthetic zeolites. Vol. 1: Crystallization. New York: Gordon and Breach Science Publishers; 1990.

28. ASTM C109. Compressive strength of hydraulic cement. West 
Conshohocken, PA, USA: ASTM International; 2009.

29. Ozvan A, Tapan M, Erik O, Efe T, Depci T. Compressive strength of scoria added Portland cement concretes. Gazi Univ. J. Sci. 2012;25:769-775.

30. Zaharaki D, Komnitsas K. Effect of additives on the compressive strength of slag-based inorganic polymers. Global Nest J. 2009;11:137-146.

31. Komnitsas K, Zaharaki D, Perdikatsis V. Effect of synthesis parameters on the compressive strength of low-calcium ferronickel slag inorganic polymers. J. Hazard. Mater. 2009;161: 760-768.

32. Yip CK, Lukey GC, Provis J, Van Deventer JSJ. Effect of calcium silicate sources on geopolymerisation. Cement Concrete Res.
2008;38:554-564.

33. İnan Sezer G. Compressive strength and sulfate resistance of limestone and/or silica fume mortars. Constr. Build. Mater. 2012;26:613-618.

34. Kamarudin H, Mustafa Al Bakri AM, Binhussain M, et al. Preliminary study on effect of $\mathrm{NaOH}$ concentration on early age compressive strength of kaolin-based green cement. In: International Conference on Chemistry and Chemical Process IPCBEE 2011 May. 2011;10:18-24.

35. Ilić B, Radonjanin V, Malešev M, Zdujić M, Mitrović A. Study on the addition effect of metakaolin and mechanically activated kaolin on cement strength and microstructure under different curing conditions. Constr. Build. Mater. 2017;133:243-252. 